\title{
REVIEW
}

\section{Healing the wounds of marine mammals by protecting their habitat}

\author{
Giuseppe Notarbartolo di Sciara ${ }^{1, *}$, Erich Hoyt ${ }^{2}$ \\ ${ }^{1}$ IUCN Marine Mammal Protected Areas Task Force and Tethys Research Institute, Viale G.B. Gadio 2, 20121 Milano, Italy \\ ${ }^{2}$ IUCN Marine Mammal Protected Areas Task Force and Whale and Dolphin Conservation, Park House, Allington Park, \\ Bridport DT6 5DD, UK
}

\begin{abstract}
Important marine mammal areas (IMMAs) - 'discrete habitat areas, important for one or more marine mammal species, that have the potential to be delineated and managed for conservation' (IUCN Marine Mammal Protected Areas Task Force 2018, p. 3) - were introduced in 2014 by the IUCN Marine Mammal Protected Areas Task Force to support marine mammal and wider ocean conservation. IMMAs provide decision-makers with a user-friendly, actionable tool to inform them of the whereabouts of habitat important for marine mammal survival. However, in view of their non-prescriptive, evidence-based and biocentric nature, the conservation effectiveness of IMMAs is strictly dependent on politicians' willingness to make use of them. It has been the customary task of advocacy non-governmental organisations to lobby decision-makers to stimulate respect for environmental law, but the scientific community is increasingly joining this effort. Scientists can effectively strengthen a healthy relationship between scientific objectivity and political advocacy without damaging the credibility of conservation science. Thus, those undertaking the identification of IMMAs can be among those responsible for strongly advocating the implementation of IMMAs and other conservation initiatives.
\end{abstract}

KEY WORDS: Conservation · Marine mammals · Important marine mammal areas · IMMAs · Marine protected areas

\section{INTRODUCTION}

The oceans are being denuded of the life that supports and determines what the ocean is and what it means to humans. Many marine species may be going extinct even before they are named or properly studied (Snelgrove 2010). The problems of habitat degradation and destruction, chemical and noise pollution, disturbance from ship traffic and the escalating signs of climate disruption define our age (Halpern et al. 2008, Notarbartolo di Sciara 2015). The Living Planet Index for marine organisms, monitoring 5829 populations from a complex of 1234 mammal, bird, reptile and fish species, shows a decline of $49 \%$ based on trends observed between

*Corresponding author: disciara@gmail.com
1970 and 2012 (Tanzer et al. 2015). The level of marine species' extinctions caused by human activities remains lower than that of terrestrial species, yet it is impossible to avoid concluding that humans have profoundly affected life in the oceans through the widespread alteration of ecosystem structure and functioning (McCauley et al. 2015, Payne et al. 2016).

Marine mammals, including cetaceans, pinnipeds, sirenians, sea otters and polar bears, are particularly vulnerable to human impacts due to their life history traits (Lotze et al. 2017). Fishermen use dolphins to find tuna and other fish, incidentally catching and killing the dolphins as part of fisheries bycatch. Others hunt whales and dolphins directly; run into them with ships; or displace or kill them with navy sonar,

() The authors 2020. Open Access under Creative Commons by Attribution Licence. Use, distribution and reproduction are unrestricted. Authors and original publication must be credited. 
seismic exploration, oil-and-gas extraction and discharges of harmful substances at sea (Avila et al. 2018). Out of a total of 130 marine mammal species, the status of $38(29.2 \%)$ is classified in the IUCN's Red List of Endangered Species in a threatened category ('Critically Endangered', 'Endangered', or 'Vulnerable'), while $31(23.8 \%)$ are still listed as 'Data Deficient' (IUCN 2020). Most populations of some large whales, such as humpback whales Megaptera novaeangliae, grey whales Eschrichtius robustus and southern right whales Eubalaena australis, have shown substantial recoveries in the decades following the decrease in hunting pressure (Clapham 2016, Zerbini et al. 2019), yet most other marine mammal populations persist only as fragments of their former abundance.

As the awareness of threats to marine mammals and other ocean species increased, the imperative emerged in multilateral environmental agreements to adopt targeted conservation policies. Marine mammals have benefitted, perhaps beyond their intrinsic conservation importance, with the consideration that these species are potent conservation icons (Parsons et al. 2015, Mazzoldi et al. 2019). Marine mammals also function as flagship and umbrella species, extending the benefits of their protection to other less visible species, thus enhancing the value of conservation action (Kalinkat et al. 2017). Agreements directed toward conserving marine mammals, amongst other species, include the Convention on International Trade in Endangered Species of Wild Fauna and Flora (CITES, signed in 1973), the Convention on the Conservation of Migratory Species of Wild Animals (Bonn Convention of 1979) and the Convention on Biological Diversity (CBD of 1992), followed by many other agreements and regulations having regional scope, and reflected in turn in widespread national legislation. On paper, most of the world's marine mammal species are protected from being killed or harassed, or having their parts traded across national borders.

Yet, even this protection means little when it comes to the exploitation of commercial fish and interaction with fishing gear, which are often the cause of marine mammal entanglements, incidental catch and depletion of their prey. Near the top of the long list of most affected taxa is the vaquita Phocoena sinus, which hovers close to extinction; various Endangered to Critically Endangered species and subspecies such as the Atlantic humpback dolphin Sousa teuszii; the North Atlantic and the North Pacific right whales E. glacialis and E. japonica; the Mediterranean and the Hawaiian monk seals Monachus monachus and
Neomonachus schauinslandi; the Maui dolphin Cephalorhynchus hectori maui; the Taiwanese humpback dolphin $S$. chinensis taiwanensis; the narrowridged finless porpoise Neophocaena asiaeorientalis; several southeast Asian riverine populations of the Irrawaddy dolphin Orcaella brevirostris (Brownell et al. 2019, Jefferson 2019); and populations of the dugong Dugong dugon across wide portions of its range (Marsh et al. 2011). Not only is all life in the ocean under full-scale attack, but also the complex conditions for life in the sea, the habitats and ecosystems, are being altered such that one day it may be impossible to reconstruct the conditions for a healthy ocean as we once knew it.

Concerned by the results of scientific investigations revealing the plight of many marine mammal species and populations, most governments and members of the public today generally want to save marine mammals. Still, translating what is on paper into action to mitigate negative effects is proving difficult in view of the 'out-of-sight, out-of-mind' nature of fisheries interactions, shipping and tourism impacts, environmental contaminants and climate disruption. There are occasional localised successes, but in most cases, these are insufficient to counter widespread population declines (Marsh et al. 2003). Conservation failures stem in large part from the false perception by decision makers that by the sole fact of having adopted conservation policies they have solved the problem (Bearzi 2020).

Several methods have been adopted to implement marine mammal conservation efforts (Twiss \& Reeves 1999). Amongst these, resorting to habitat protection has been increasingly attempted (Hoyt 2011, Notarbartolo di Sciara et al. 2016). Place-based conservation can be an effective tool for addressing threats to marine mammals (e.g. Gormley et al. 2012), although to date most marine protected area (MPA) efforts have been ecosystem-, not species-, oriented (Hoyt 2018). When it comes to whales, the prospect of protecting vast areas that cross national boundaries and span oceans beyond national jurisdictions is often impractical. One alternative is to employ protected area networks covering critical breeding or feeding habitat (Notarbartolo di Sciara et al. 2016), which often leaves migratory corridors devoid of specific protection. Aside from these issues, a more fundamental problem with marine mammal habitat protection is that vast amounts of data remain unpublished, and indeed are fairly inaccessible for use in defining habitat (Hoyt 2018). For these reasons, marine mammals remain under-represented in place-based conservation solutions around the world (Hoyt 2011). 
To facilitate the consideration of a place-based approach to marine mammal conservation, to inform decision making and to integrate conservation activities into strategic planning, a user-friendly tool was developed. The tool aimed to identify habitats using criteria based on data gathered and peer-reviewed as part of a scientifically robust process. Such a tool, serving the purpose of outlining special areas that might be beneficial to the protection of specific marine mammal populations, and addressing the wide range of challenges to marine mammal conservation when planning human activities at sea, was launched in 2014 by the IUCN Joint Species Survival Commission/World Commission on Protected Areas (SSC/ WCPA) Marine Mammal Protected Areas Task Force (hereafter the 'Task Force', www.marinemammal habitat.org). The first such tools were identified in the Mediterranean Sea in 2016. The Task Force adopted the name and matching acronym, inspired by that used for important bird and biodiversity areas, the so-called IBAs (Donald et al. 2019). Thus, the important marine mammal area (IMMA) was born (Hoyt \& Notarbartolo di Sciara 2014).

\section{IMPORTANT MARINE MAMMAL AREAS}

IMMAs are designed to identify 'discrete habitat areas, important for one or more marine mammal species, that have the potential to be delineated and managed for conservation' (IUCN Marine Mammal Protected Areas Task Force 2018, p. 3). IMMAs are meant to integrate other marine spatial assessment tools, including the CBD's ecologically or biologically significant areas, biologically important areas as set out by the US government (Ferguson et al. 2015) and Australian legislation (Commonwealth of Australia, https://bit.ly/3anSZkU) and key biodiversity areas (KBAs) identified through the global KBA Standard (IUCN 2016). IMMAs have the potential to function as a marine mammal layer, indicative of biodiversity and ecosystem health in the world's oceans and relevant inland water bodies, for consideration by governments, inter-governmental organisations, conservation groups, industry, conservation scientists and the general public (Agardy et al. 2019). Thus, IMMAs are purely advisory; not prescriptive: they are not MPAs, although they could subsequently be used in marine spatial planning and specific conservation planning that might result in MPAs or other initiatives being taken.

IMMAs are identified through a biocentric expert process that is independent of any political and socio-economic pressure or concern. Covering at this time most of the Southern Hemisphere and a small portion of the Northern Hemisphere (IUCN Marine Mammal Protected Areas Task Force 2020) (Fig. 1), the present 158 IMMAs have been identified through international expert consultation and consensus. Regional workshops were held in the Mediterranean (2016), the Pacific Islands (2017), the North East Indian Ocean and South East Asian Seas (2018), the Extended Southern Ocean (2018), the Western Indian Ocean and Arabian Seas (2019), and the Australia, New Zealand and South East Indian Ocean region (2020). A workshop investigating the

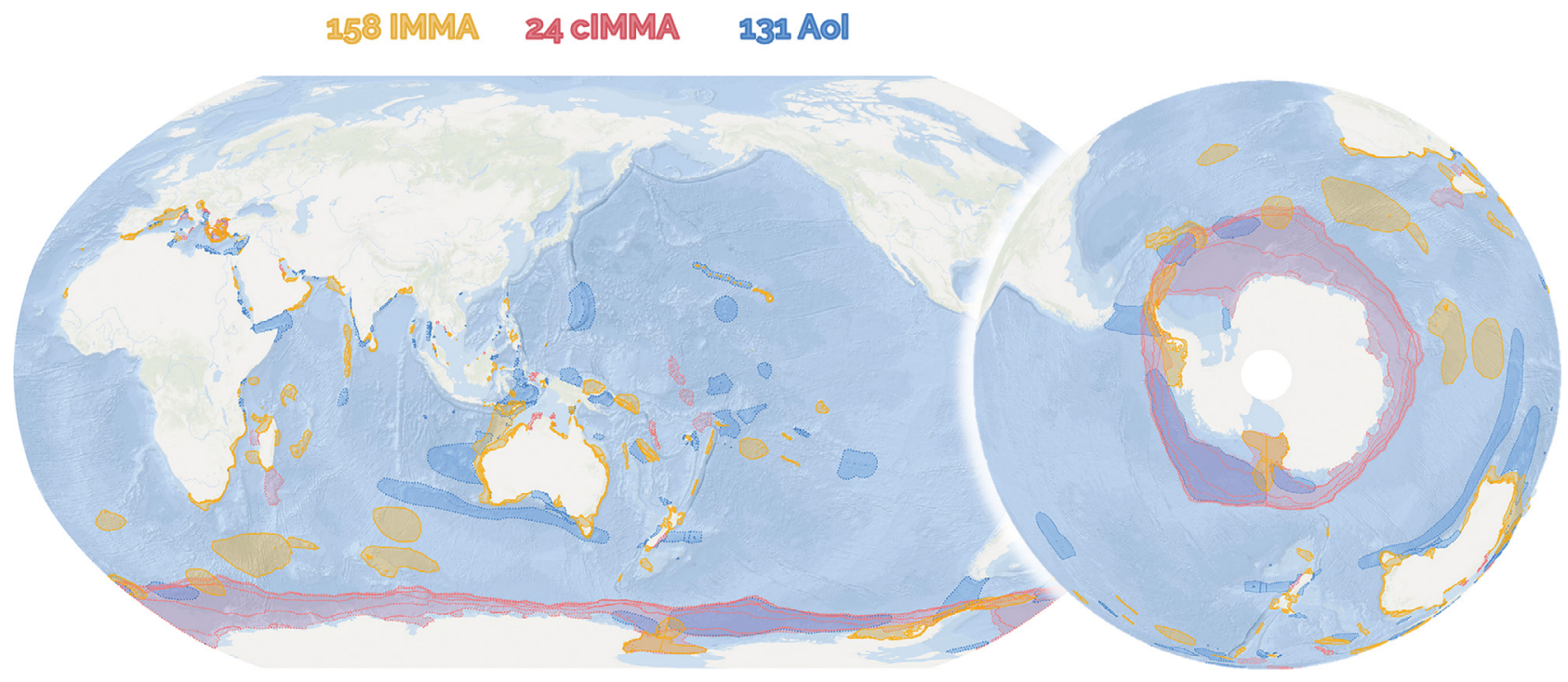

Fig. 1. World distribution of important marine mammal areas (IMMAs; yellow), candidate IMMAs (cIMMAs; pink) and 'Areas of Interest' (AoIs; blue), as of August 2020 (derived from https://www.marinemammalhabitat.org/immas/imma-eatlas/) 
South East Temperate and Tropical Pacific Ocean is planned for early 2021.

IMMAs are identified on the basis of 4 main criteria (species or population vulnerability; distribution and abundance; key life cycle activities; and special attributes such as distinctiveness and diversity) designed to capture critical aspects of marine mammal biology, ecology and population structure (IUCN Marine Mammal Protected Areas Task Force 2018). Only one criterion is needed to identify an IMMA, but that criterion must be supported by robust data.

The identification of IMMAs is performed on a region by region basis (Notarbartolo di Sciara et al. 2016). Initially, a call for submissions of 'Areas of Interest' (AoIs) in a particular region is broadly advertised and solicited within the scientific and conservation practitioners' communities; submissions are accepted from any person or institution. If the AoIs have one or more criteria that can be defended by data, they are then elaborated as candidate IMMAs (cIMMAs) during the regional expert workshops. Having undergone independent peer review after the regional workshop, if the criteria have been successfully met, cIMMAs formally become IMMAs and are posted on the e-Atlas (Fig. 1) and in an online searchable database. A CIMMA that has not reached a sufficient level of robustness but only needs minor adjustments to become an IMMA (adjustments that can be made without resubmission to a successive workshop) maintains its status as a cIMMA and is shown as such on the e-Atlas (Fig. 1); in contrast, cIMMAs that need substantial additional knowledge and a reassessment including new collective scrutiny through a workshop and review are posted on the e-Atlas as AoIs (Fig. 1). To address the concern that unstable environmental conditions including climate change, distributional changes in a population and increasing ecological knowledge are likely to render original IMMA designations less useful and potentially obsolete (Agardy et al. 2019), a regionbased review is built into the identification process with the aim that this should recur every 10 years.

\section{BEYOND DRAWING BOUNDARIES ON THE WORLD MAP}

Michelangelo sculpted his Pietà with a chisel. Yet, with only a chisel untouched by Michelangelo's hand, humans would have been deprived of the expression of his artistic genius. Like Michelangelo's chisel, IMMAs are but a tool, and can contribute little to the effort of enhancing marine mammal conservation status unless they are used by policy makers, decision makers and the various marine stakeholders. Unless IMMAs are used as a conservation tool, they are condemned to join other tools in the junk closet of 'marine conservation on paper' (Bearzi 2020).

However, despite peer-reviewed and approved IMMAs having been around for only 3 years, their buy-in by a diverse array of stakeholders has been encouraging. As of early 2020, the Task Force had received 79 requests for IMMA shapefiles and metadata. Such requests, per se, are not proof of use, but they are an indicator of potential conservation action. Amongst requesters, 35\% were from universities or were other academic researchers, 22\% were from non-governmental organisations (NGOs), 20\% from industry or business, 18\% from government and 5\% from inter-governmental organisations. Most of the requests $(41 \%)$ were motivated by a declared conservation intent, though the stated research and educational purposes, as well as some of the commercial purposes, would have conservation outputs as well. Positive conservation examples include (1) 2 proposed MPAs in Vietnam that received helpful support and acknowledgment of their value through IMMA identification, and (2) the agreement by the International Whaling Commission, following a joint workshop with the Task Force and the Convention on Migratory Species' (CMS) Agreement on the Conservation of Cetaceans of the Black Sea, Mediterranean Sea and Contiguous Atlantic Area (ACCOBAMS) in 2019, of utilising IMMAs in the identification and mitigation of ship strike threats to large whales.

Yet, there are also cases where IMMAs have been failing in their conservation intent. A large area of southern and southwestern Greece, in coastal and offshore waters, was recently granted by the Greek government as a concession to the oil and gas industry for hydrocarbon exploration and exploitation (Fig. 2). The concession area extends from the northeastern Ionian Sea to south of Crete, covering approximately $56000 \mathrm{~km}^{2}$ (WWF-Greece 2019). This area overlaps to a significant extent with 2 IMMAs identified by the Task Force in 2016: the first, the 'Ionian Archipelago IMMA' (Fig. 2), was identified for Mediterranean monk seals and common dolphins Delphinus delphis. The second, the 'Hellenic Trench IMMA' (Fig. 2), contains core habitat for Cuvier's beaked whales Ziphius cavirostris and for the last remaining sperm whales Physeter macrocephalus in the eastern Mediterranean Sea (Notarbartolo di Sciara 2016). All of these marine mammal subpopulations are assessed as Endangered in the IUCN Red List, with the exception of Cuvier's beaked whales, which are rated 'Vulnerable'. As these species are listed in 


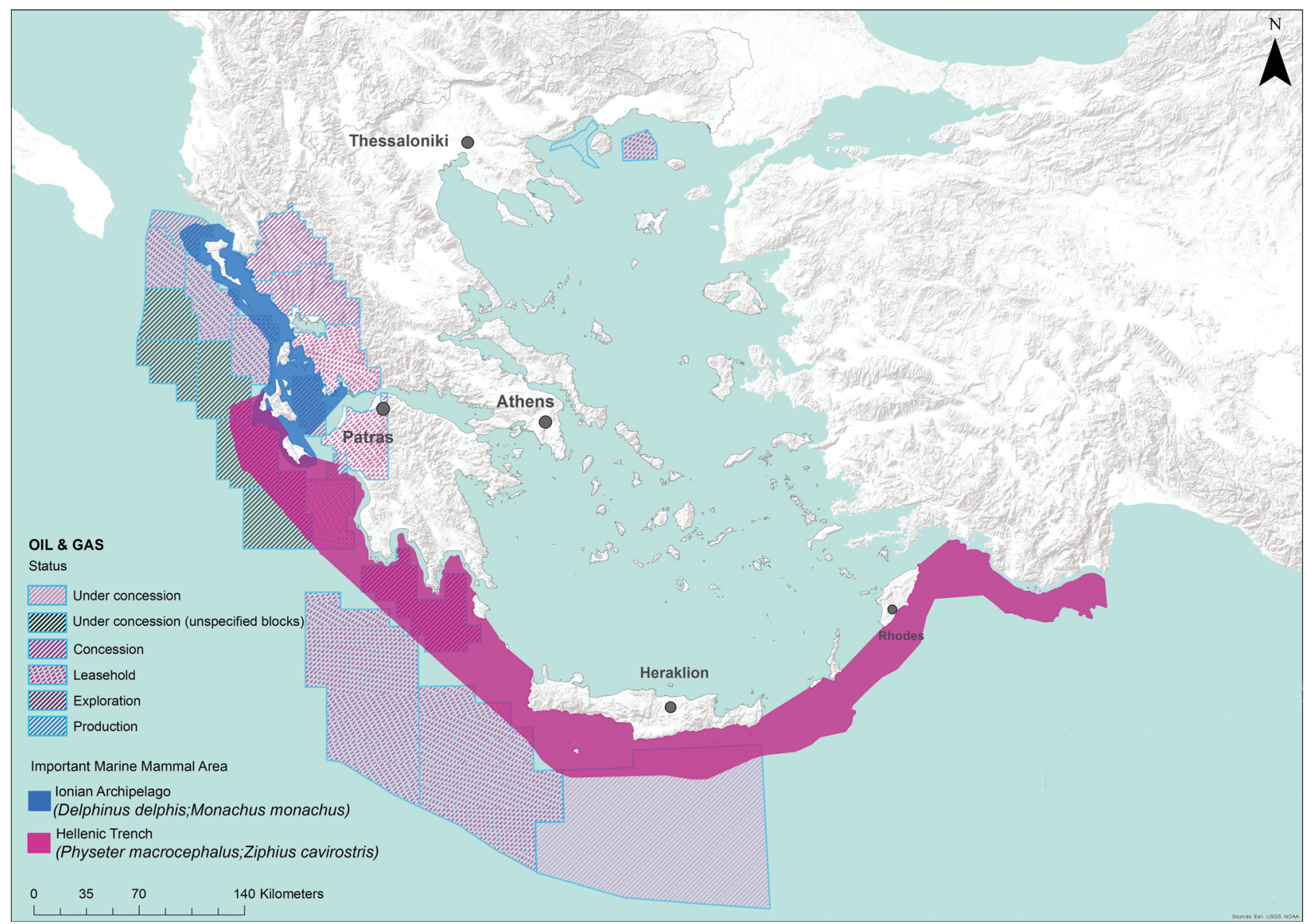

Fig. 2. 'Ionian Archipelago' important marine mammal area (IMMA) (blue), the 'Hellenic Trench' IMMA (pink) and oil and gas development concessions ('Under concession' = pending; 'Concession' = finalised) awarded by the Government of Greece (map courtesy of Oikoskopio.gr, WWF-Greece, modified)

Annex IV of the Habitats Directive 92/43/EEC, which includes 'animal and plant species of community interest in need of strict protection', it is a clear obligation for Greece to ensure good conservation status of these species in their habitats included within the country's jurisdictional waters.

Another example of government-sanctioned activities occurring in, or planned to occur in, an IMMA can be found in the 'Bazaruto Archipelago to Inhambane Bay IMMA' which was identified for dugongs along the southern coast of Mozambique. Listed globally as 'Vulnerable' in the IUCN Red List, the dugong population off East Africa likely merits the more extreme 'Endangered' status (H. Marsh pers. comm). The species has almost completely disappeared from much of East Africa and Madagascar, persisting today in small, scattered numbers from Egypt to Mozambique - numbers too small to maintain a healthy population and thus likely to disappear in the near future. Only the waters of the Bazaruto Archipelago extending north to Inhambane Bay harbour a still healthy population estimated at between 250 and 350 individuals (Cockcroft et al. 2018). This is now the last known viable dugong population in East Africa. In part recognizing the need for dugong protection as well as the value of ecotourism, the Mozambique government protected the Bazaruto Archipelago in 1971 as a national park, which is administered by African Parks. However, the scientific conclusion from the 'Bazaruto Archipelago to Inhambane Bay IMMA' identification is that $70 \%$ of the area's dugongs live outside of the boundaries of the national park where they are (1) at extreme risk of entanglement in illegal gillnets and (2) within the footprint of proposed oil and gas developments. Should the Bazaruto dugong population become extinct, dugongs would likely soon be extirpated from the entirety of Africa's coastal waters.

In both of the above cases, governments are faced with a choice between respecting their own environmental obligations and promoting productive activities, such as in oil and gas exploration and exploitation at sea, that they believe will have a positive 
outcome on their economies. Marine hydrocarbon development, in addition to well-known impacts on climate, causes detrimental effects to marine mammals by inducing behavioural disruption (habitat exclusion) and even physiological damage, due to active introduction of noise into the marine environment as well as adding to marine traffic, which poses a significant risk from ship collisions (Weilgart 2007). Yet, Greece, Mozambique and many other governments may persist with all-out development as if the presence of protected species' habitat there, and of an IMMA designation, were unknown to regulators.

\section{A VISION EXTENDING BEYOND HABITAT PROTECTION}

Moving the identification of IMMAs to implementation on the ground, from science to actual conservation, was anticipated as a slow but deliberate process. As noted above, there is some movement, yet the speed at which it is happening is ill-matched to the rate at which some of the marine mammal populations in IMMAs are declining.

Dissecting the problem, we find that there is a complex transition from the non-prescriptive IMMA identification to the incorporation by the relevant authorities of IMMA-derived ecological knowledge into management planning and eventually the implementation of effective designations or laws. This transition can take years, particularly when the establishment of an effective marine protected area is part of the process. To achieve the ultimate goal of having a real effect on the lives and habitats of the relevant marine mammals, careful coordination, even choreography, is needed among all players on the local to the national and even the global level. The players, or active members of human societies, can be deconstructed into 3 broad components: scientists, politicians, and civil society. Scientists, focussing on nature or conservation issues, detect problems, indicate solutions and offer tools to implement solutions. In the case of IMMAs, the role of the Task Force is to put the IMMAs on the world map based on a rigorous and transparent process, thereby making relevant scientific knowledge available in an actionable, userfriendly fashion to politicians and managers.

Politics is the art of compromise. The politicians' challenge is to strike an often-elusive balance between development and conservation (Apostolopoulou \& Adams 2015), ensuring (1) that management occurs sustainably, (2) that human activities at sea that have the potential of harming marine mammals are regulated, and (3) that rules are enforced. All are required in order to minimise environmental damage and ensure that the legal obligations concerning protected species are respected.

In an ideal world, with societal agreement on the essential values of nature, and the stakeholders welcoming a triage-like process for rapid implementation, the system could work well, harnessing a proactive interaction between science and politics. Science identifies the habitats authoritatively, in this case IMMAs, and the government establishes legal MPAs or imposes zoning or other restrictions to address threats to the environment and improve the conservation outcomes. However, history has shown how political compromises bend, twist and distort this interaction. Indeed, in many cases, the science is ignored completely by the politicians. The results swing dramatically towards the development side, with token regard for the conservation of nature, if that. The result, in the worst cases, is in effect the abandonment of a species, or population, by allowing a habitat to be exploited beyond recognition, or condemned to a slow death by degrees over time.

The loss of opportunity can be avoided by intervention from the third societal component-civil society - including those stakeholders working in support of non-governmental advocacy organisations that act as watchdogs of government action in defence of the environment. Even in the young IMMA world, we see them at work in the growing number of IMMA metadata requests received by the Task Force from NGOs. Clearly motivated by conservation, these requests provide an indicator of the willingness of a portion of civil society to use IMMAs to support marine mammal place-based conservation. At the same time, however, industry, led by well-funded lobbyists, marketers and executives, will sometimes try to negate the efforts of NGOs.

The matter then gets handed to government to make decisions, but increasingly conservation scientists (including ecologists, conservation biologists, taxonomists, botanists and zoologists) have also been called upon, as well as voluntarily agreeing, to take an advocacy role. In terms of conservation advocacy for species and ecosystems, things began to change in the 1980s when leading scientists such as Thomas Lovejoy, with WWF-US, Peter Raven from the Missouri Botanical Garden, Oxford's Norman Myers, Harvard's E. O. Wilson and others started using the word 'biodiversity' to focus theoretical debate on conservation issues (Franco 2013). Biologist Daniel H. Janzen, part of this group but the only one living full time in the tropical forest (in Costa Rica), went 
further. In an article entitled 'The Future of Tropical Ecology' and in a legendary address to biologists, Janzen urged scientists to undertake much needed political activism for conservation, with the stated threat that if they failed to take on a role beyond only science there would be no species left to study (Janzen 1986, Franco 2013).

Today, a participatory approach and advocacy role by subjects who are involved as scientists in designing or implementing an MPA experience growing acceptance within the scientific community (Gray \& Campbell 2009). Conservation policy is a vital link between science and politics, and maintaining a healthy relationship between scientific objectivity and political advocacy without damaging conservation science's credibility is becoming an accepted practice (Horton et al. 2016). Natural or conservation scientists may refer to this dual role as 'wearing different hats'.

This concept is well exemplified by the IMMA process. IMMAs are identified and defined strictly on the basis of data and on how well the available evidence satisfies the scientific criteria. Adherence to scientific objectivity in the identification of IMMAs is further ensured by having candidate IMMAs proposed by regional expert workshops followed by independent review before approval. Once the process is complete, however, and an IMMA is engraved on the world map, nothing prevents those who have been involved in its identification from changing hats and now advocating application, so that the primary goal of ensuring that marine mammals can benefit from their right to habitat is realised and their survival is secured.

IMMA identification captures what nature generally, and marine mammals more specifically, need us to hear: there are priority areas that require our immediate conservation attention. Through the science-mediated interpretation of empirical observations made in marine mammal habitat, many scientists feel that they are entrusted with this information. It therefore becomes an imperative that carries a moral obligation to do everything possible to ensure that marine mammal spaces are not only identified, but respected, even preserved. This may be partly fuelled by a sense of guilt for the damage that our species is inflicting on the planet that hosts us and all other forms of life, but pushes most of these species off the cliff.

At the same time, conservation scientists today recognize the importance of extending the conservation focus from populations to individual animals. This shift in conservation emphasis is driven by an increasing understanding of the conservation value of the animals' social learning and cultural transmission of behaviour, particularly in those cases in which the survival of key individuals, depositaries of special knowledge, confers unique conservation value to the community (Brakes et al. 2019). A special focus on the individual may have grown out of photographic identification (photo-ID), the starting point for hundreds of studies on marine mammals beginning in the 1970s (Wells 2018). The importance of individuals to the survival of the group is revealed especially when there are low numbers of individuals comprising a population (e.g. the cases of the North Atlantic right whale Eubalaena glacialis and the southern community of killer whales Orcinus orca), such that all individuals are known and followed through their life history. Eventually, ethical considerations may spring naturally from a focus on the individual. Many conservation scientists and practitioners today strive not merely to ensure that species and populations can survive within their habitats and ecosystems, but also to grant individual marine mammals a right to their habitat based on a lifestyle unperturbed by human effects, and where they can enjoy an environmental quality as close as possible to the conditions they have evolved to live in (Hoyt 2017). It has been argued that marine mammals, and cetaceans in particular, meet the requirements for possessing 'personhood, e.g., being alive; being aware; having positive and negative sensations, emotions, and a sense of self; controlling one's own behaviour; recognizing other 'persons' individually and treating them appropriately: and possessing a variety of sophisticated cognitive abilities' (White 2007), and that if this argument is accepted, then cetaceans 'are persons and should be given rights somewhat similar to those of humans' (Whitehead \& Rendell 2015).

We live today in a world divided by those people exploiting species and ecosystems and those embracing widespread societal changes resulting from urgent concerns for the state of the planet. The imperative of acting in remediation, and an increasing empathy for the plight of non-human animals, has moved into the mainstream. Perhaps Aldo Leopold's (1993) lamented loneliness ('one of the penalties of an ecological education is that one lives alone in a world of wounds') is finally becoming a thing of the past, with natural scientists no longer afraid of expanding their remit from being descriptors of the planet's diseases, to more boldly assuming the role of doctors engaged in implementing the cure. In such a scenario, the IMMAs can be taken as a case in point. Yes, they are an expression of a highly specialised science-based undertak- 
ing, but they can point the way to addressing one aspect of the planetary malaise. Although only one aspect, IMMAs are, however, tied together with other specialised conservation tools and initiatives which, taken together and supported by scientists and stakeholders, have the potential of helping to achieve a global, comprehensive, multidisciplinary and ultimately effective global conservation strategy.

Acknowledgements. We gratefully acknowledge the help of Dimitris Ibrahim, WWF Greece, in providing details about the oil and gas developments in Greece, and of Michael J. Tetley for providing the IMMA world map. We are also grateful for the suggestions of 3 anonymous reviewers, who helped to significantly improve this article.

\section{LITERATURE CITED}

Agardy T, Cody M, Hastings S, Hoyt E, Nelson A, Tetley M, Notarbartolo di Sciara G (2019) Looking beyond the horizon: an early warning system to keep marine mammal information relevant for conservation. Aquat Conserv 29: 71-83

Apostolopoulou E, Adams WM (2015) Neoliberal capitalism and conservation in the post-crisis era: the dialectics of 'green' and 'un-green' grabbing in Greece and the UK. Antipode 47:15-35

Avila IC, Kaschner K, Dormann CF (2018) Current global risks to marine mammals: taking stock of the threats. Biol Conserv 221:44-58

Bearzi G (2020) Marine biology on a violated planet: from science to conscience. Ethics Sci Environ Polit 20:1-13

Brakes P, Dall SRX, Aplin LM, Bearhop S and others (2019) Animal cultures matter for conservation. Science 363: 1032-1034

Brownell RL Jr, Reeves RR, Read AJ, Smith BD and others (2019) Bycatch in gillnet fisheries threatens Critically Endangered small cetaceans and other aquatic megafauna. Endang Species Res 40:285-296

Clapham PJ (2016) Managing leviathan: conservation challenges for the great whales in a post-whaling world. Oceanography 29:214-225

Cockcroft VG, Guissamulo AT, Findlay K, West L, Mohamed MOS, Taju A, Hadi A (2018) Dugongs (Dugong dugon) of the Western Indian Ocean Region: identity, distribution, status, threats and management. Final Report to WIOMSA, April 2018. www.cms.int/sites/default/files/document/ cms-dugong_mos3_pres_wiomsa-project_guissamulo.pdf

Donald PF, Fishpool LDC, Ajagbe A, Bennun LA and others (2019) Important Bird and Biodiversity Areas (IBAs): the development and characteristics of a global inventory of key sites for biodiversity. Bird Conserv Int 29: $177-198$

Ferguson MC, Curtice C, Harrison J, Van Parijs SM (2015) Biologically Important Areas for cetaceans within U.S. waters - overview and rationale. Aquat Mamm (Spec Issue) 41:2-16

Franco JL de A (2013) The concept of biodiversity and the history of conservation biology: from wilderness preservation to biodiversity conservation. História (São Paulo) $32: 21-48$
Gormley AM, Slooten E, Dawson S, Barker RJ, Rayment W, du Fresne S, Bräger S (2012) First evidence that marine protected areas can work for marine mammals. J Appl Ecol 49:474-480

Gray NJ, Campbell LM (2009) Science, policy advocacy, and marine protected areas. Conserv Biol 23:460-468

* Halpern BS, Walbridge S, Selkoe KA, Kappel CV and others (2008) A global map of human impact on marine ecosystems. Science 319:948-952

*Horton CC, Peterson TR, Banerjee P, Peterson MJ (2016) Credibility and advocacy in conservation science. Conserv Biol 30:23-32

Hoyt E (2011) Marine protected areas for whales, dolphins and porpoises. A world handbook for cetacean habitat conservation and planning, $2^{\text {nd }}$ edn. Earthscan/Taylor \& Francis, London

Hoyt E (2017) Encyclopedia of whales, dolphins and porpoises. Firefly Books, Buffalo, NY

Hoyt E (2018) Marine protected areas. In: Würsig B, Thewissen JGM, Kovacs KM (eds) Encyclopedia of marine mammals, $3^{\text {rd }}$ edn. Academic Press/Elsevier, San Diego, CA, p 569-580

Hoyt E, Notarbartolo di Sciara G (eds) (2014) Report of the workshop for the development of Important Marine Mammal Area (IMMA) criteria. IUCN Marine Mammal Protected Areas Task Force and International Committee on Marine Mammal Protected Areas, Marseille, France, 22 Oct. 2013. https://bit.ly/2TWIIHc

IUCN (2016) A global standard for the identification of Key Biodiversity Areas, Version 1.0. IUCN, Gland

IUCN (2020) The IUCN Red List of Threatened Species. Version 2019-3. www.iucnredlist.org (accessed 30 April 2020)

IUCN Marine Mammal Protected Areas Task Force (2018) Guidance on the use of selection criteria for the identification of Important Marine Mammal Areas (IMMAs). Version: March 2018. https://bit.ly/2Umm4Ho

IUCN Marine Mammal Protected Areas Task Force (2020) IMMA e-Atlas. https://www.marinemammalhabitat.org/ immas/imma-eatlas/

Janzen DH (1986) The future of tropical ecology. Annu Rev Ecol Syst 17:305-324

Jefferson TA (2019) Endangered odontocetes and the social connection: selected examples of species at risk. In: Würsig B (ed) Ethology and behavioral ecology of odontocetes. Springer Nature, Switzerland, p 465-482

Kalinkat G, Cabral JS, Darwall W, Ficetola F and others (2017) Flagship umbrella species needed for the conservation of overlooked aquatic biodiversity. Conserv Biol 31:481-485

Leopold A (1993) Round River. Oxford University Press, New York, NY

K Lotze HK, Mills Flemming J, Magera AM (2017) Critical factors for the recovery of marine mammals. Conserv Biol 31:1301-1311

Marsh H, Arnold P, Freeman M, Haynes D and others (2003) Strategies for conserving marine mammals. In: Gales N, Hindell M, Kirkwood R (eds) Marine mammals: fisheries, tourism and management issues. CSIRO Publishing, Collingwood, p 1-19

Marsh H, O'Shea TJ, Reynolds JE (2011) Ecology and conservation of the Sirenia: dugongs and manatees. Cambridge University Press, Cambridge

Mazzoldi C, Bearzi G, Brito C, Carvalho I and others (2019) From sea monsters to charismatic megafauna: changes in 
perception and use of large marine animals. PLOS ONE 14:e0226810

McCauley DJ, Pinsky ML, Palumbi SR, Estes JA, Joyce FH, Warner RR (2015) Marine defaunation: animal loss in the global ocean. Science 347:1255641

Notarbartolo di Sciara G (2015) Marine conservation. In: Smith HD, Suarez de Vivero JL, Agardy TS (eds) Routledge handbook of ocean resources and management. Routledge, London, p 145-156

Notarbartolo di Sciara G (2016) Marine mammals in the Mediterranean Sea: an overview. Adv Mar Biol 75: $1-36$

Notarbartolo di Sciara G, Hoyt E, Reeves RR, Ardron J, Marsh H, Vongraven D, Barr B (2016) Place-based approaches to marine mammal conservation. Aquat Conserv 26(Suppl 2): 85-100

* Parsons ECM, Baulch S, Bechshoft T, Bellazzi G and others (2015) Key research questions of global importance for cetacean conservation. Endang Species Res 27:113-118

Payne JL, Bush AM, Heim NA, Knope ML, McCauley DJ (2016) Ecological selectivity of the emerging mass extinction in the oceans. Science 353:1284-1286

Snelgrove P (2010) Discoveries of the census of marine life: making ocean life count. Cambridge University Press, Cambridge

Editorial responsibility: Konstantinos Stergiou, Thessaloniki, Greece
Tanzer J, Phua C, Lawrence A, Gonzales A, Roxburgh T, Gamblin P (eds) (2015) Living blue planet report: species, habitats and human well-being. WWF and Zoological Society of London. https://www.worldwildlife.org/ publications/living-blue-planet-report-2015

Twiss JR, Reeves RR (eds) (1999) Conservation and management of marine mammals. Smithsonian Institution Press, Washington and London

*Weilgart LS (2007) The impacts of anthropogenic ocean noise on cetaceans and implications for management. Can J Zool 85:1091-1116

Wells R (2018) Identification methods. In: Würsig B, Thewissen JGM, Kovacs KM (eds) Encyclopedia of marine mammals. Academic Press/Elsevier, San Diego, CA, p 503-509

White TI (2007) In defense of dolphins: the new moral frontier. Blackwell Publishing Ltd, Hoboken, NJ

Whitehead H, Rendell L (2015) The cultural lives of whales and dolphins. University of Chicago Press, Chicago, IL

WWF-Greece (2019) Oil and gas frenzy threatens Greek nature. https://bit.ly/2zgz1eR

K Zerbini AN, Adams G, Best J, Clapham PJ, Jackson JA, Punt AP (2019) Assessing the recovery of an Antarctic predator from historical exploitation. R Soc Open Sci 6: 190368

Submitted: April 24, 2020; Accepted: June 26, 2020

Proofs received from author(s): August 14, 2020 